ISSN 1112-9867

Available online at $\quad$ http://www.jfas.info

\title{
INCREASING THE AVAILABILITY OF URBAN PASSENGER TRANSPORT ON OBJECTIVE CONTROL DATA BASIS
}

\author{
I. F. Suleimanov ${ }^{*}, 1$, G. V. Mavrin ${ }^{1}$, M. R. Kalimulina ${ }^{1}$, I. I. Liubimov², A. N. Melnikov², A. \\ A. Filippov ${ }^{2}$ \\ ${ }^{1}$ Kazan Federal University, Naberezhnye Chelny Institute \\ ${ }^{2}$ Orenburg State University
}

Published online: 08 August 2017

\begin{abstract}
Urban passenger road transport has an important socio-economic significance, ensuring mobility of the population. The quality of passenger road transport is characterized by the availability, safety and the level of public satisfaction.

Urban transportation is subject to the state and industry standards that regulate quality indicators. A significant number of works in our country and abroad have been devoted to the study of the problem of ensuring the quality of passenger road transport. The issues of ensuring the quality of transportation by the methods of dispatching the operation of passenger vehicles, based on objective control data remain insufficiently studied.

The research was carried out using elements of the theory of system analysis and decision theory, mathematical modeling, probability theory and mathematical statistics, expert evaluation theory, field surveys, linear and nonlinear programming, and the theory of road transportation.

The paper presents the results of the development of a mathematical model of the quality of passenger road transport, taking into account the relationship of objective control data with the parameters of the rolling stock and the route network.

The designed model is intended for development of methods and means of operative management of a rolling stock on route based on variation of external factors forming passenger traffic.
\end{abstract}

Author Correspondence, e-mail: ecolog_777@mail.ru

doi: http://dx.doi.org/10.4314/jfas.v9i2s.81 
The developed theoretical provisions and practical recommendations are intended for use by both dispatch departments of motor transport enterprises and dispatch centers coordinating the work of the whole route network of a settlement.

\section{Keywords}

Passenger transport, safety of passenger transport, road transport enterprises

\section{INTRODUCTION}

The most important indicator of the social and economic stability of the region is the reliable, safe and efficient work of urban passenger transport (UPT). The leading place in the UPT system belongs to bus passenger traffic.

However, in recent times, the UPT has been characterized by a certain decrease in the quality of transport services to the population, primarily due to the physical and moral aging of the vehicle fleet, which further negatively affects the safety of passenger traffic.

Under these circumstances, the stable operation of the UPT can be provided by existing methods for ensuring the availability and quality of car passenger traffic, which efficiency depends on the complex of organizational and technological solutions used in dispatching control systems.

Ensuring the reliable functioning of the UPT is a complex problem. Obviously, it cannot be solved without the use of modern control systems, designed on the basis of the latest advances in computer science, with the extensive use of computer equipment, mobile communication and navigation.

Thanks to the development of satellite navigation systems and telematics facilities, it became possible to design and implement radically new dispatch control systems that meet the everincreasing requirements for reliability, safety and quality of urban passenger traffic.

The paper deals with the investigation of the properties and structure of the quality component of transportation - the accessibility of passenger transport services.

Objective of the study is the reliability of the functioning of urban passenger transport on the basis of the formation of organizational and technological decisions of the dispatch management aimed at eliminating the consequences of deviations in the actual parameters of the passenger traffic process from the set ones.

To achieve this goal, the following tasks must be solved:

1) identification and analysis of factors affecting the effectiveness of the dispatch system to eliminate deviations in the parameters of the transportation process from the set ones; 
2) a mathematical analysis of the time costs of the dispatch system when searching for and using a backup passenger vehicle;

3) development of algorithms for making managerial decisions by the dispatcher, which minimize the time for eliminating the consequences of critical situations and shifts in the passenger traffic process;

4) development of practical recommendations for improving the organizational and technological support of the dispatch management of urban passenger transport.

The study is based on the results of previous studies $[1,2,3,5,6]$. These works deals with the questions of quality of organizational-technological infrastructure of car passenger traffic and the operation technical parameters of a rolling stock on routes. The issues of investigating the relationship between the objective control data, the parameters of the rolling stock operation and the characteristics of the route network remained unexamined [11, 12, 14, 15, 16, 17].

\section{METHODS}

To study the relationship between the objective control data and the parameters of the rolling stock and route network, a mathematical model has been developed.

Quality index of transport operation $Q$ is determined by the formula:

$$
Q=\sum_{1}^{n} \gamma_{i} Q_{i}
$$

where $\gamma_{i}$ is the weighting factor of the i-th component of the quality index; $Q_{i}$ - the i-th component of the quality index; $n$ - the number of components of the quality index.

The existing $[4,7,8,9]$ components of the quality index include indicators of information service, comfort, speed, timeliness, safety of luggage, and security. It is proposed to introduce one more indicator - the availability of passenger traffic services.

The availability is proposed to be used under the integral indicator $Q_{d j}$, which includes indices of economic (price) availability, technical accessibility, territorial accessibility, temporary availability, information availability of services, as well as the index of the satisfied demand for urban car passenger traffic services:

$$
Q_{d}=\sum_{1}^{m} \gamma_{j} Q_{d j}
$$

where $\gamma_{j}$ is the weighting factor of the $\mathrm{j}$-th component of the availability indicator; $Q_{d j}$ is the $\mathrm{j}$ th component of the availability indicator; $m$ is the number of components of the availability indicator. 
Values of weight coefficients are established by experts in the field of urban passenger car operation by a priori ranking of factors.

The rolling stock monitoring system uses technical means integrated into the existing transport network.

Forecasting the development of road transport, it is necessary, along with research in the field of vehicle development, to analyze the main fields of the development of the motor transport network and determine its characteristics. In general, the mathematical model of a motor transport network is described as follows.

Let $P$ - be an arbitrary finite set of elements $P_{i}, D-$ be the collection of some (not necessarily all) ordered pairs $d_{i j}=\left(p_{i}, p_{j}\right)$, each of which is composed of different elements of the set $P$. The set of two sets $P$ and $D$ is called the motor transport network $(P, D)$ and is said to be given or generated by these sets.

Elements $p_{i}$ of the set $P$ are called points of the motor transport network $(P, D)$, the elements $d_{i j}=\left(p_{i}, p_{j}\right)$ of the set $D$ are called network communications.

The communication $d_{i j}$ connects points $p_{i}$ and $p_{j}$, starting at $p_{i}$ and ending at $p_{j}$. Thus, to specify a motor transport network is to indicate a set of its points and a communication system under the given restrictions. If for some $i$ and $j$ the network contains communications $d_{i j}$ and $d_{j i}$, then they are called opposite.

An arbitrary motor transport network can be represented by a matrix, which elements $d_{i j}$ are calculated according to the rule

$$
d_{i j}=\left\{\begin{array}{l}
1, \text { if communication } d_{i j} \in D ; \\
0, \text { otherwise }
\end{array}\right.
$$

The matrix of the motor transport network presented below uniquely determining its topology shows points allowed for the transportation from the points corresponding to this line. Columns of the matrix allow identifying communications that end at fixed points. Each point cannot accept more than its traffic capacity. The matrix of the transport network features the following conditions.

$$
\begin{array}{llllllll}
P_{1} & P_{2} & P_{3} & P_{4} & P_{5} & P_{6} & P_{7} & P_{8}
\end{array}
$$




$\begin{array}{ccccccccc}P_{1} & 0 & 1 & 0 & 0 & 0 & 1 & 1 & 1 \\ P_{2} & 0 & 0 & 1 & 0 & 0 & 0 & 0 & 0 \\ P_{3} & 0 & 1 & 0 & 1 & 0 & 0 & 0 & 0 \\ P_{4} & 0 & 0 & 0 & 0 & 0 & 1 & 0 & 0 \\ P_{5} & 0 & 0 & 1 & 0 & 0 & 0 & 0 & 1 \\ P_{6} & 0 & 1 & \mathrm{I} & 0 & 0 & 1 & 0 & 0 \\ P_{7} & 1 & 1 & 0 & 0 & 1 & 0 & 0 & 0 \\ P_{8} & 0 & 0 & 0 & 1 & 1 & 0 & 0 & 1\end{array}$

The main elements of the motor transport network are units (ATP) and links (routes).

The interaction of the road transport system (RTS) with the surrounding (external) environment is carried out through the entrances and exits and is represented by the canonical model.

List of entrances:

$X_{1}$ - information: planned tasks for the volume of traffic; technical descriptions, operating instructions, technological equipment;

$X_{2}$ - material (object): the flow of cargo and passengers to be transported;

$X_{3}$ - power; newly introduced vehicle type (buses, trucks, cargo bays of passenger buses used for mixed transport, temporarily converted cars for other types of transport); buildings and constructions; electricity and fuel to ensure production activities; fuel and and lubricants; technological equipment; financial and other material resources;

$X_{4}$ - staff;

$X_{5}$ - indignation, disturbing the planned work of the system (unplanned conditions and restrictions imposed by the interests of the individual subject, random changes in demand, conditions and restrictions imposed on the system by nature, etc.).

List of exits:

$y_{1}$ - information: information on the implementation of the plan; information on the technical means and financial condition of the system; single information requests;

$y_{2}$ - material (object): passengers and cargoes delivered to the destination, pass-km, t-km;

$Y_{3}$ - power: dropout of the rolling stock and individual elements (according to the plan, due to resource wear or malfunction); loss of energy; wear of process equipment; wear of 
buildings and structures;

$Y_{4}$ - staff: temporary lack of work for staff (rest); loss of staff;

$Y_{5}$ - indignation: unplanned impact on a particular component of the industry; change in the terms of delivery of cargoes and passengers; environmental pollution; negative impact on the population, etc.

The objectives of the system and the limitations on the resources needed for their implementation are actually laid in the future and annual plans for the operation of road networks, which include, in a more detailed form, most of the system's links with the environment.

\section{RESULTS}

In order to determine the most significant components of the quality index of transport operation, evaluated by objective control methods, a study was conducted by the method of a priori ranking of factors. Eight experts were asked to rank six factors. As a result, the most significant factor was the timely delivery of the vehicle to the station point. The data of experts are consistent with the concordance coefficient $W=0.72$.

The next most important factor is the availability of passenger traffic services as an opportunity to achieve the specified goal of the trip with minimal time and money.

To determine the number of buses required on the route, a known dependence is used, where the static capacity utilization factor is replaced by the variable $\gamma_{c a p}(t)$, which characterizes the value of the coefficient at time $t$ :

$$
A=\frac{365 \cdot Q_{p} \cdot \gamma_{c a p}(t) \cdot \alpha_{r} \cdot V_{\text {exp }} \cdot T_{\text {ord }} \cdot \beta}{l_{a v} \cdot k_{h} \cdot k_{t r}},
$$

where $Q_{p}$ - the annual volume of traffic on the route, pass.;

$l_{a v}$ - average passenger travel distance, $\mathrm{km}$;

$k_{h}, k_{t r}$ - traffic unevenness coefficient according to the hours of the day and the routes;

$\gamma_{\text {cap }}(t)$ - the vehicle's capacity factor at time $t$;

$\alpha_{r}-$ the vehicle's capacity factor;

$V_{\text {exp }}$ - operating speed, $\mathrm{km} / \mathrm{h}$;

$T_{\text {ord }}$ - duration of stay of the vehicle on duty, $\mathrm{h}$;

$\beta$ - the vehicle mileage utilization factor.

The bus traffic interval $I$, min, is determined by the formula: 


$$
I=\frac{T_{f r}}{A},
$$

where $T_{f r}$ - the time of the turnaround run.

The traffic interval as a function of the capacity utilization factor is determined by the formula:

$$
I=f\left(\gamma_{\text {cap }}\right) .
$$

The capacity utilization factor $\gamma_{c a p}$ is determined by the formula:

$$
\gamma_{\text {cap }}=\frac{q_{p}^{\text {fact }}}{q_{p}^{\max }},
$$

where $q_{p}^{\text {fact }}-$ actual number of passengers, pass.;

$q_{p}^{\max }$ - bus passenger capacity, pass.

The result of the formation of the traffic interval control model, which provides the implementation of the specified parameters, is the expression (8):

$$
\begin{gathered}
Q_{p}=\frac{365 \cdot A \cdot q_{p}^{\max } \cdot \alpha_{r} \cdot V_{\text {exp }} \cdot T_{\text {ord }} \cdot \beta}{l_{a v} \cdot q_{\text {max }} \cdot k_{h} \cdot k_{\text {tr }}} \rightarrow \max \\
I_{\min }<I<I_{\max } ; \\
I=\left\{\begin{array}{l}
\uparrow, \text { if } \gamma_{\text {cap }} \geq 0,8 ; \\
\downarrow, \text { if } \gamma_{\text {cap }}<0,8 .
\end{array}\right.
\end{gathered}
$$

Practical implementation of the developed model implies a reduction in the interval of bus traffic at passenger capacity close to the maximum and an increase in the interval with insufficient capacity $[1,2,3,13]$.

Based on the generated mathematical model, an algorithm for the adaptive management of buses on the city routes was developed.

The results of modeling the road transport network were used to manage such components of the transport quality indicator as timeliness and speed of transportation.

\section{SUMMARY}

The developed mathematical model of adaptive management of buses on city routes is based on the interrelation of bus performance on the route with the capacity utilization factor, which makes it possible to use the operative correction of the rolling stock on the route.

The operation is adjusted by changing the interval of bus traffic on the basis of information 
obtained by means of objective control.

\section{CONCLUSION}

Practical implementation of the developed theoretical provisions forms the program of priority research in the following areas:

- analysis of the features of various intellectual technologies and methods of processing the information obtained on the degree of occupancy of the bus interior in relation to management tasks;

- development of theoretical principles of intellectual management;

- development of principles for building hardware and software for intelligent control systems.

Large-scale research in this area will provide the opportunity to create a fundamentally new generation of technology designed for autonomous operation in the conditions of incomplete and uncertain incoming information in the presence of random perturbations of the external environment.

\section{ACKNOWLEDGEMENTS}

The work is performed according to the Russian Government Program of Competitive Growth of Kazan Federal University.

\section{REFERENCES}

1. Analysis of technical means of car passenger traffic monitoring / E.V. Bondarenko, I.I. Liubimov, A.N. Melnikov, N.A. Trubin // Progressive technologies in transport systems: a collection of materials of the X International Scientific and Practical Conference (April 24-26, 2013). - Kumertau: Kumertau city printing house, 2013. - p. 60-65.

2. The concept of management of municipal road transportations / Bondarenko E.V., Goncharov A.A., Gorlatov S.E., Liubimov I.I., Manaev K.I., Melnikov A.N., Trubin N.A. // The World of Transport and Technological Machines, 2015. - No. 2 (49). - p. 110-116.

3. Prerequisites for the improvement of the organization of urban passenger transport / E.V. Bondarenko, I.I. Liubimov, A.N. Melnikov, N.A. Trubin // Progressive technologies in transport systems: a collection of materials of the X International Scientific and Practical Conference (April 24-26, 2013). - Kumertau: Kumertau city printing house, 2013. - p. 65-68.

4. Theoretical study of the indicator "dynamic passenger dimensions" / Iakunin N.N., 
Iakunina N.V., Kuisokov T.A. // Intellect. Innovation. Investments. - 2016. - No. 1. - p. 9597.

5. Trubin N.A. Prerequisites for the introduction of adaptive management of road transport / N.A. Trubin // Bulletin of Orenburg State University, 2014. - No.10. p. 183-187.

6. Formation of the purpose and objectives of the study of adaptive passenger traffic management / E.V. Bondarenko, I.I. Liubimov, A.N. Melnikov, N.A. Trubin // Progressive technologies in transport systems: a collection of materials of the X International Scientific and Practical Conference (April 24-26, 2013). - Kumertau: Kumertau city printing house, 2013. - p. 60-65.

7. Iakunin N.N., Iakunina N.V., Shakhalevich G.A. Road transport certification: a textbook - Orenburg: OSU, 2015. - p. 583.

8. Iakunina N.V. Methodology of improving the quality of car passenger traffic on regular routes: Monograph. - Orenburg: IPK Universitet LLC, 2015. - p. 262.

9. Iakunina N.V. Car passenger traffic on regular routes: Theoretical basis of the methodology of quality improvement // Standards and quality - 2015. - No. 2. - p. 92-93.

10. Car sharing systems as a sustainable transport policy: A case study from Lisbon, Portugal / Baptista, P., Melo, S., Rolim, C. // Transport and Sustainability. Volume 7, 2015, Pages 205-227.

11. Control of robotic mobility-on-demand systems: A queueing-theoretical perspective / Zhang, R., Pavone, M. // International Journal of Robotics Research.Volume 35, Issue 1-3, 1 January 2016, Pages 186-203.

12. Estimation of Passenger Car Equivalents for single-lane roundabouts using a microsimulation-based procedure / Giuffrè, O., Granà, A., Tumminello, M.L., Sferlazza, A. Expert Systems with Applications. Volume 79, 2017, Pages 333-347.

13. Lyubimov I.I., Melnikov A.N., Trubin N.A. The Control System Improvement of the City Motor Transportation Science Direct: Procedia Engineering. - 2016. - Volume 150. Pp. 1192-1199.

14. Multimodal transport model: Enhancing collaboration among mobility sharing schemes by identifying an optimal transit station / Prashanth, T.S.L., Tamilselvan, A.K., Chandrodaya, S. // 2016 International Conference on Internet of Things and Applications, IOTA 2016. Pages 286-291.

15. Topology-regularized universal vector autoregression for traffic forecasting in large urban areas / Schimbinschi, F., Moreira-Matias, L., Nguyen, V.X., Bailey, J. // Expert 
Systems with Applications. Volume 82, 2017, Pages 301-316.

16. Traffic state estimation based on Eulerian and Lagrangian observations in a mesoscopic modeling framework / Duret, A., Yuan, Y. // Transportation Research Part B: Methodological. Volume 101, 2017, Pages 51-71.

17. Urban passenger transport problems in Dar es Salaam, Tanzania / Banyikwa, W.F. // African Urban Quarterly. Volume 3, Issue 1-2, 1988, Pages 80-93.

How to cite this article:

Suleimanov I F, Mavrin G V, Kalimulina M R, Liubimov I I, Melnikov A N, Filippov A A. Increasing the availability of urban passenger transport on objective control data basis. J. Fundam. Appl. Sci., 2017, 9(2S), 1067-1076. 